\title{
Comprehensive scientific and technical programs as a vector of education development in the digital economy
}

\author{
Natalya Fedorova ${ }^{1,2}$, Yuriy Danilchenko ${ }^{1,2}$, Vladislav Kukartsev ${ }^{1,2}$, Vadim Tynchenko ${ }^{1,2, *}$, Larisa Korpacheva ${ }^{2}$, \\ and Danil Gek ${ }^{1}$ \\ ${ }^{1}$ Reshetnev Siberian State University of Science and Technology, 31 Krasnoyarsky Rabochy av., Krasnoyarsk, Russia \\ ${ }^{2}$ Siberian Federal University, 79 Svobodny pr., Krasnoyarsk, Russia
}

\begin{abstract}
New global challenges in the development of the economy, and as a result, in education, have led to changes in the requirements for forms and methods of teaching, for the content of educational programs, which requires the involvement of a wider range of practitioners and the adaptation of education to the standards of the digital economy. Under the influence of globalization processes, both the nature of the international competitiveness of countries and the nature of competitive advantages are changing, focusing on human capital, new forms of management, digital information. The vector of development of education is integrated scientific and technical programs that unite educational and scientific organizations with enterprises of the real sector. To this end, on the basis of higher education institutions, whose main goal is to provide professional personnel for the territory, scientific education centres are created that contribute to the introduction of an innovative approach to solving socio-economic problems of the region, provide comprehensive support for innovative initiatives of entrepreneurs and organizations, and methodological and consulting support for subjects small and medium businesses on the development of innovative entrepreneurial projects.
\end{abstract}

\section{Introduction}

The process of changing a social or government structure, which involves finding new properties that correspond to the current level and nature of technology development, is called modernization [1]. In varying degrees, modernization is an integral part of the development process of any state. Currently, we are witnessing not only the evolution of technical means, but also the emergence of a new configuration of the economic system - the digital economy, which, in turn, is an important condition for the economic well-being and national security of the country $[2,3]$.

The greatest success in this direction have been achieved by such countries as the Netherlands, Great Britain, South Korea, the Scandinavian trio - Norway, Denmark, Sweden. Moving to the digital economy is a global trend. Within the framework of this paradigm, a model of Russia's development is being built. The President of Russia, representatives of big business and top managers of important banking institutions support of the digitalization of the domestic economy [4]. Intensive development and introduction of new technologies set fundamentally different tasks for education [5].

The Strategy for the Development of the Information Society in the Russian Federation for 2017-2030 defines the digital economy as an economic activity in which the key factor in production is digital data, processing large volumes and using the results of analysing them in comparison with traditional forms of business can significantly improve efficiency various types of production, technology, equipment, storage, sale, delivery of goods and services [6].

In modern economics, information plays a dual role: it is both a resource (a production factor) and a final good (a product) [7]. At the same time, a product in an information society can be represented in three types: data that is the result of analysis; an information digital product; a knowledge base [8]. Information has two features [9]:

- The presence of the law of increasing marginal utility due to the effect of the direct network effect.

- Negligibly small marginal costs that trigger the effect of increasing profitability.

All this indicates that the implementation of the information product is limited only by the capacity of the market.

The main objective of the state is to improve the welfare and quality of citizens' life. The level of welfare and quality of citizens' life ultimately determines the country's competitiveness. There are various approaches of determining the competitiveness of a country.

American economist Michael Porter argued that "the most important goal of any country is to create a high and ever-increasing standard of living for its citizens". A country's ability to achieve this goal depends on how productively the resources and capital is used [10].

\footnotetext{
${ }^{*}$ Corresponding author: vadimond@,mail.ru
} 
When considering the term "competitiveness", several levels of its study should be distinguished [11]:

- Microeconomic. Competitiveness of goods or Competitiveness of the company.

- Mezoeconomic. Competitiveness of the region.

- Macroeconomic. Competitiveness of the country.

Levels are increasingly transforming under the influence of globalization

Globalization creates cooperation (internationalization of production), and cooperation creates competitive advantages. The international competitiveness of the economy implies the assessment of the country, firstly, as an autonomous system consisting of a number of interrelated subsystems; secondly, as a separate subject of the world economy, entering into international competitive relations with other subjects [12].

\section{Impact of globalization processes on competitiveness}

Under the influence of globalization processes, both the nature of the international competitiveness of countries and the nature of competitive advantages are changing, focusing on human capital, new forms of management, digital information. The vector of development of education is integrated scientific and technical programs that unite educational and scientific organizations with enterprises of the real sector.

To this end, on the basis of higher education institutions, whose main goal is to provide professional personnel for the territory, scientific education centres are created that contribute to the introduction of an innovative approach to solving socio-economic problems of the region, provide comprehensive support for innovative initiatives of entrepreneurs and organizations, and methodological and consulting support for subjects small and medium businesses on the development of innovative entrepreneurial projects. In the conditions of digitalization of the economy, these centres contribute to the improvement of the educational process through the introduction of innovative mechanisms, tools and technologies, as well as the creation and testing of prototypes (pilot projects) of teaching methods involving students in this process.

The most significant trends in the development of competition beginning of the XXI century are:

- Necessity to note the transition from price to non-price factors of competition.

- Change in the structure of consumer and investment demand (transition from mass unified products to individualized demand).

- Significant market segmentation.

- Production diversification with a focus on innovative development.

As a result, "intensive" factors of international competitiveness prevail in the modern economy knowledge, human capital, information technologies, flexible production, and new forms of management [13].
In general, the definition of 38 place (Table 1) for Russia in the 2017-2018 year raises questions about the objectivity of the calculations, however, a significant positive trend should be noted (five years ago in 2012, Russia occupied the 67th place in the Global Competitiveness Rating).

The competitiveness of a country is formed by competitive enterprises. The task of determining competitive enterprises and industries is also ambiguous. The fact is that the industry structure is increasingly losing its relevance.

Enterprises, formally referring to certain industries, diversify their economic activities.

Thus, the types of economic activity have replaced the branches.

Table 1. Russia's ranking in global competitiveness.

\begin{tabular}{|c|c|c|}
\hline Rating & Economy & Index \\
\hline 1 & Switzerland & 5.9 \\
\hline 2 & USA & 5.9 \\
\hline 3 & Singapore & 5.7 \\
\hline 4 & Netherlands & 5.7 \\
\hline 5 & Germany & 5.7 \\
\hline$\cdots$ & $\cdots$ & $\cdots$ \\
\hline 37 & Malta & 4.6 \\
\hline 38 & Russia & 4.6 \\
\hline 39 & Poland & 4.6 \\
\hline 40 & India & 4.6 \\
\hline
\end{tabular}

New information technologies (IT) lead to further erosion of industries and diffusion of the enterprise's structure. New information technologies unite competition and cooperation in a strategic alliance - joint preparation and implementation of an innovation and investment project without creating permanent management services and restricting competitive independence [14].

So, the goal of our research is to determine the forms of integration of modern high-tech enterprises, science and education to carry out effective work and to obtain a synergistic effect and prospects for successful implementation in the global digital economy.

Figure 1 shows contributions of event groups to IT development. 


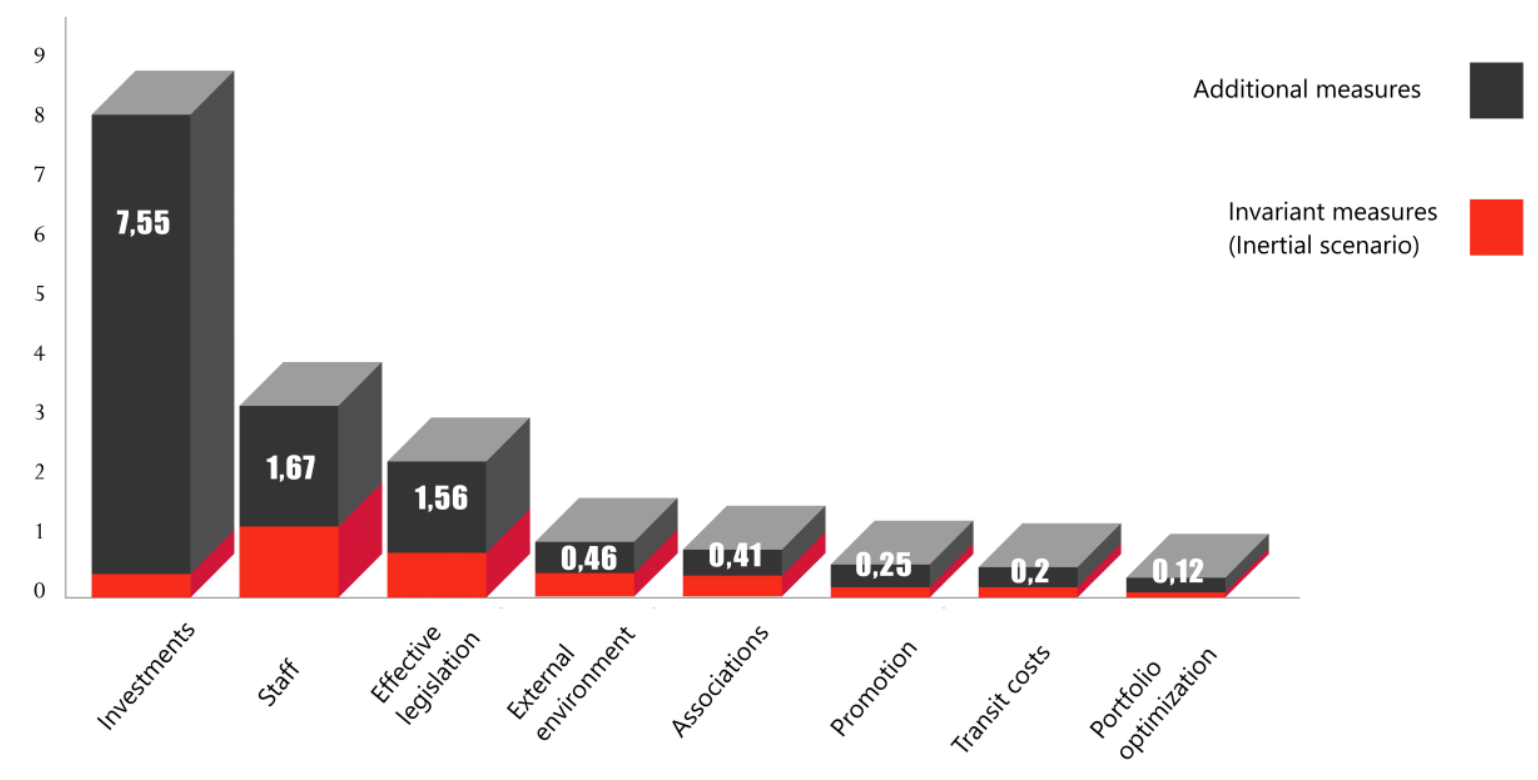

Fig. 1. Contributions of event groups to IT development

\section{Elements of the digital economy development}

Digitalization has replaced IT and computerization, transforming business models of modern enterprises even more. The great digital representation of information leads to the fact that it forms already holistic technological environments of "habitat" (ecosystems, platforms). The special properties of digital information led to the emergence of a digital economy [15].

Personnel stand out as one of the most important elements in the development of the digital economy. The development of human resources is in second place in the contribution to the development of the digital economy after investment $[16,17]$.

In this regard, the importance of higher education in the formation of relevant competencies among specialists directly involved in the digital economy, and among developers of information technologies that provide the infrastructure of the digital economy.

The "growth points" of future competitiveness are complex scientific and technical programs and projects representing end-to-end technologies that, due to their versatility, have a high multiplicative effect, affecting the entire production process - from obtaining new fundamental knowledge to production and bringing it to the consumer. Such prospects do not seem to be a near reality for many domestic companies.

The integrated program (integrated project) is a set of activities coordinated by tasks, time and resources, including research and the stages of the innovation cycle prior to the creation of technologies, products and services. At present, the implementation of comprehensive programs and projects is actively supported by the state, financing is planned from both the federal budget (appropriate funds are provided for in state programs), as well as from regional, local budgets and extra budgetary sources.

One of such integrated science and technology programs could be the creation of a science and education centre (SEC) "Space systems and advanced production technologies", based on the integration of universities and research organizations and their cooperation with enterprises operating in the real economy (Fig. 2) [18].

The initiators of the creation are the Siberian Branch of the Russian Academy of Sciences and JSC Information Satellite Systems named after Academician M.F. Reshetnev "with the support of the State Corporation" Roscosmos").

The main university partner in the creation of SECs are Siberian State University of Science and Technology named after Academician M.F. Reshetnev - supporting university of Krasnoyarsk and the Siberian Federal University.

The goal of the SEC is to create in the Russian Federation an integrated system of personnel, scientific and technological support for the development of the space industry and other breakthrough areas based on a combination of the educational process, research and development and implementation of innovative projects in the interests of high-tech enterprises.

Objectives of the SEC:

- Implementation of the Research and Development Program (RDP) - full-cycle projects for the benefit of industrial partners.

- Creation of an integrated system of personnel training for enterprises of the military-industrial complex and the space industry.

- Development of a joint research, educational and innovation infrastructure. 


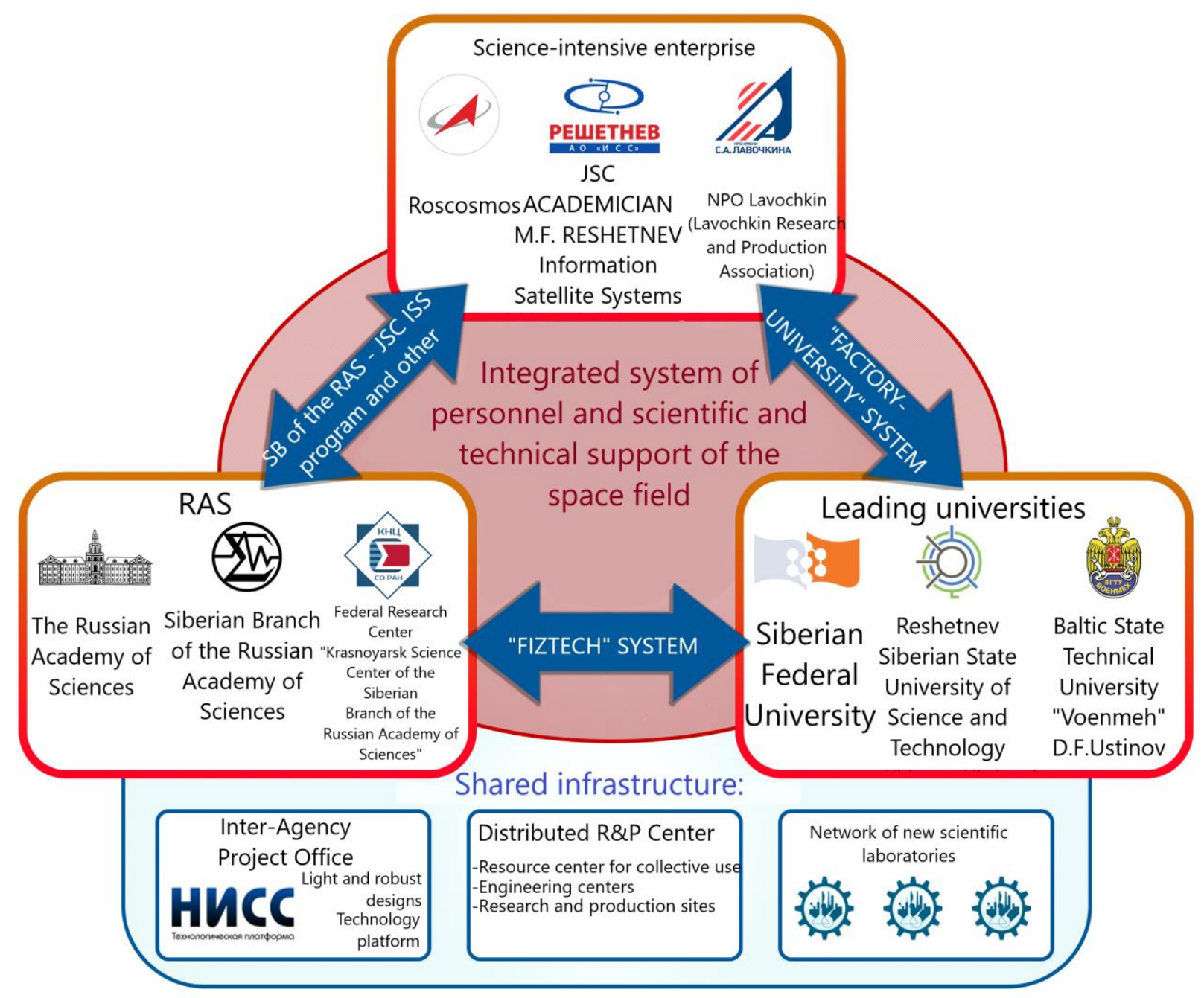

Fig. 2. The concept and model of inter-sectoral and interregional SEC "Space information systems and technologies"

The results of the SEC "Space Information Systems and Technologies" activities by educational organizations will be the development of an integrated system of personnel training through:

- Systematic participation of basic enterprises in the program of the university development.

- Participation of representatives of basic enterprises in the development of educational programs of the university.

- Coordination of curricula by basic enterprises.

- Creating a system of basic departments in the territory of the base enterprises.

- Combinations of the educational process of students with work in a basic enterprise (work experience, other forms).

- Participation of all target students in R\&D with remuneration.

The interaction of universities and businesses belongs to the main modern trends in the development of higher education. Studying and generalizing domestic and international experience in building qualification and education development systems, developing, improving and introducing innovative educational technologies taking into account the requirements of the regional market and the capabilities of higher education institutions will create a favourable basis for the development of large and small businesses in the Russian economy in modern digital the economy.

\section{Conclusions}

Due to complex scientific and technical programs, we will not only give impetus to the development of those sectors of the Russian economy that are now competitive due to natural conditions, but also create a basis for the formation of future world market leaders - new hightech and service industries (in the broad sense of concepts).

This suggests that this topic is very relevant and promising in its content. It requires a thorough study of the integration issues of innovative enterprises, leading universities, customers, whose joint work is supported by the state, and generally aims at improving the competitiveness of Russian enterprises in the global market. Such work can be financed from the federal budget (appropriate funds are provided through the state programs), as well as from the regional, local budgets and extra-budgetary sources.

\footnotetext{
${ }^{\text {* Corresponding author: vadimond } @ \text { mail.ru }}$
} 


\section{References}

1. E.A. Khitskov, S.V. Veretekhina, A.V. Medvedeva, E.G. Shmakova, A. Kotenev, Eurasian J. of Analyt. Chem. 12, 5 (2017)

2. A. Porter, Country competitive advantages (International economics, Moscow, 2006)

3. S. Vasin, L. Gamidullaeva, E. Shkarupeta, I. Palatkin, T. Vasina, Eur. Res. Stud. J. 21, 3 (2018)

4. V.G. Khalin, A.V. Yurkov, Y.V. Kosov, Communications in Comp. and Inf. S., 745 (2017)

5. V.V. Kukartsev, E.A. Chzhan, V.S. Tynchenko, O.A. Antamoshkin, A.A. Stupina, J. of Sib. Fed. Uni. - Hum. and Soc. S. 11, 5 (2018)

6. E. Lyapuntsova, Y. Belozerova, I. Drozdova, G. Afanas'Ev, E. Okunkova, MATEC Web of Conf., 251 (2018)

7. I. Pavlekovskaya, A. Urintsov, O. Staroverova, Y. Nefedov, Proc. of the Eur. Conf. on Knowl. Man., 2 (2018)

8. I.M. Golova, A.F. Sukhovey, Econ. of Reg. 14, 3 (2018)

9. A. Bereznoy, R. Saygitov, Vestnik Ros. Akad. Med. Nauk 71, 3 (2016)

10. M.I. Galvanovsky, I.V Bushmarin, V.M. Zhukovskaya, Russia's competitiveness in the 90s. Cross-country macroeconomic analysis (RAS Institute for World Economy and International Relations, Moscow, 2000)
11. V.V. Putin, Russian newspaper. Retrieved from: http://www.rg.ru/2012/01/30/putin-ekonomika.html (Jan 30 2012)

12. V.I. Anikin, Competitiveness of Russia, priorities of strategic cooperation with foreign countries and challenges for national security (Russian Institute for Strategic Studies, Moscow, 2013)

13. Global Competitiveness Index. Retrieved from: https:/gtmarket.ru/ratings/global-competitivenessindex/info (2019)

14. L.S. Blyakhman, Three colors of economic time: achievements and problems of the Russian economy (CPI SPGUTD, Saint-Petersburg, 2011)

15. T.O. Tolstykh, E.V. Shkarupeta, I.A. Shishkin, O.V. Dudareva, N.N. Golub, Adv. in Int. Sys. and Comp., 622 (2018)

16. The development of the digital ecosystem: direct and indirect effects for the economy. Retrieved from: http://www.forecast.ru/_ARCHIVE/Presentations/D Belousov/2018-03-31IT-ECO.pdf (2018)

17. Yu.V. Danilchenko, N.V. Fedorova, Mod. the dev. of socio-econ. pot. of the terr. in the cont. of modern chall. (2018)

18. The concept and model of inter-sectoral and interregional REC "Space information systems and technologies". Retrieved from: http://sbras.ru>files/news/docs/ohotkin_21_02_2019. $\operatorname{pdf}(2019)$ 